\title{
Motivos para Participação em Tarefas Investigativas na Aula de \\ Matemática: uma análise a partir dos backgrounds e dos foregrounds de um grupo de estudantes do Ensino Fundamental
}

\author{
Motives for participation in Investigative Mathematics Tasks in the \\ Classroom: an analysis from the backgrounds and foregrounds of a group \\ of students from an elementary school
}

Edmilson Minoru Torisu*

ORCID iD 0000-0001-7383-387X

\begin{abstract}
Resumo
Este artigo traz à baila uma discussão em torno dos motivos de estudantes para participação em tarefas investigativas na aula de Matemática, a partir de seus backgrounds e foregrounds. Motivos foram considerados em uma perspectiva histórico-cultural como algo que emerge no interior das relações sociais. Os sujeitos desse estudo qualitativo foram quatro estudantes do nono ano de uma escola pública da cidade de Belo Horizonte, Minas Gerais, Brasil. Os dados foram coletados por meio de uma entrevista e uma entre-vista, esta segunda com o objetivo de acessar backgrounds e foregrounds dos estudantes. Os resultados da análise mostraram que, além de motivos explícitos, ao entre-vistar backgrounds e foregrounds vários outros motivos, ligados a várias vivências em grupos sociais, revelaram-se.
\end{abstract}

Palavras-chave: Motivos. Background. Foreground. Educação Matemática.

\begin{abstract}
This article presents a discussion of the motives for students to take part in investigative tasks in mathematics classes, from their backgrounds and foregrounds. The motives motives were considered in a cultural historical perspective as emerging within social relations. The participants were four students from the ninth grade of a public school in Belo Horizonte, Minas Gerais, Brazil. The data were collected through an interview and an inter-view, the second in order to access backgrounds and foregrounds of students. The analysis results showed that, in addition to explicit motives, to inter-view backgrounds and foregrounds, many other motives linked to various social groups experiences were revealed.
\end{abstract}

Keywords: Motives. Background. Foreground. Mathematics Education.

\section{Introdução}

\footnotetext{
* Doutor em Educação - Linha de Pesquisa: Educação Matemática - pela Universidade Federal de Minas Gerais (UFMG). Professor Adjunto do Departamento de Educação Matemática e Professor do Programa de Pósgraduação em Educação Matemática da Universidade Federal de Ouro Preto, Ouro Preto, Minas Gerais, Brasil. Endereço para correspondência: Rua Quatro, 786, Bauxita, sala 1-09 (ICEB III), Ouro Preto, Minas Gerais, Brasil, CEP: 35400-000. E-mail: edmilson@iceb.ufop.br.
} 
Muitos professores, sobretudo de Matemática, têm se queixado da falta de interesse de seus alunos durante as aulas. Na tentativa de reverter esse quadro, alguns procuram alternativas para tornar o ensino mais atrativo, de modo que os alunos se sintam mais motivados.

De acordo com Bzuneck (2010), a motivação no contexto escolar tem sido estudada sob várias perspectivas e, como consequência, surgiram muitas teorias e abordagens para a sua discussão. Talvez a mais utilizada seja a dos embelezamentos motivacionais (AMES, 1992; BERGIN, 1999) indicada para provocar interesse pelas atividades consideradas monótonas pelos estudantes e amenizar a aridez de alguns conteúdos. Estudos com essa abordagem são importantes e têm ajudado muitos professores em sala de aula. Entretanto, neste artigo, meu interesse é estudar a motivação relacionada ao conceito de motivo, como algo que move o indivíduo a fazer algo. Nesse sentido, estou interessado em saber quais são os motivos de um grupo de quatro estudantes para o envolvimento em tarefas investigativas na aula de Matemática e analisar o surgimento desses motivos a partir de seus backgrounds e foregrounds.

Para Skovsmose et al. (2009), o background de um indivíduo refere-se às suas raízes culturais e sociopolíticas e o foreground, à interpretação pessoal de suas perspectivas de aprender e viver, de acordo com o contexto sociopolítico-econômico no qual está inserido. De acordo com esses mesmos autores, "a motivação para o aprendizado está relacionada ao background e ao foreground de cada indivíduo" (SKOVSMOSE et al., 2009, p. 240). A afirmação que compõe esta citação vem ao encontro do objeto deste artigo, porque conecta motivos de um indivíduo ao seu background e ao seu foreground.

Propostas diferenciadas como tarefas investigativas na aula de Matemática, muitas vezes, surgem como alternativa às aulas de resolução de exercícios. Às vezes, as investidas do professor no sentido de criar esses novos ambientes de aprendizagem ${ }^{1}$ trazem bons resultados. Mas por que os alunos participam? O professor pode supor que seja porque sua proposta é diferente e, sendo assim, a tarefa e a Matemática nela contidas, seriam os motivos para a participação. Pode ser, mas seriam esses os únicos motivos?

A partir de uma perspectiva histórico-cultural, centrada nas ideias de Vygotsky e alguns de seus discípulos, os motivos são de caráter social e surgem nas atividades das quais o indivíduo participou/participa em dado momento histórico e podem ser vários. Podemos pensar em motivos individuais, mas eles emergem das relações sociais e, muitas vezes, são reinterpretados pelo indivíduo. Isso corrobora a ideia de Chaiklin (2012, p. 219) que nos alerta para o fato de que "motivo é um conceito individual e coletivo. Indivíduos podem ter motivos,

\footnotetext{
${ }^{1}$ Ambientes de aprendizagem estão sendo compreendidos na perspectiva de Skovsmose (2000), como sendo as condições nas quais os estudantes são estimulados e convidados a participarem de certas atividades.
} 
mas a individualidade dos motivos é sempre tecida dentro da prática social”. Sendo assim, para saber os motivos dos estudantes devemos ter uma visão ampliada de suas vidas e, em boa medida, isso pode ser obtido investigando seus backgrounds e foregrounds.

Pelo exposto, minha discussão será norteada pelas palavras-chave: motivos, background, foreground e, por isso, dedicarei a seção 2 à discussão desses conceitos. Logo depois, na seção 3, apresentarei aspectos metodológicos do estudo. Em seguida apresentarei os dados e os analisarei. Por fim, farei algumas considerações.

\section{Motivos, background, foreground}

Dentro da abordagem histórico-cultural para motivos, há várias perspectivas de análise. Muitos pesquisadores têm dedicado esforços à compreensão dos motivos em práticas sociais nas quais os indivíduos se desenvolvem, como família, escola, trabalho, etc. Nessa práticas, outros construtos, como emoções e identidade, são frequentemente associados aos motivos, sobretudo em pesquisas na área da Psicologia.

Estudos como o de Hedegaard (2012) mostram como podem surgir motivos nas atividades de família. A pesquisadora analisou atividades cotidianas das quais as crianças participam, como dever de casa, jantar à mesa, e concluiu que os seus motivos para tal participação têm relação com valores institucionais e familiares. A partir dessa conclusão, uma criança que ainda não tenha iniciado a vida escolar, por exemplo, ao ver seu irmão mais velho fazendo seu dever de casa, pode desenvolver motivos para brincar de fazer dever, por perceber que isto é algo valorizado socialmente.

Das interações, durante as brincadeiras, também podem emergir motivos. Medina e Martinez (2012) verificaram que as interações contribuem para o surgimento de motivos em crianças e que a forma de organização desse espaço de brincadeiras varia de lugar para lugar, refletindo valores e normas do mundo dos adultos de cada local. Partindo da mesma hipótese, de que os ambientes de brincadeira são potenciais fontes de motivos, Corsaro e Rizzo (1988) estudaram crianças americanas e italianas e observaram que, em ambos os países, elas desenvolveram uma série de comportamentos para proteger seus espaços de possíveis interferências. De acordo com Medina e Martinez (2012, p. 103), essas pesquisas mostram como as crianças,

através de suas interações, criam uma dinâmica social que sugere a reprodução do mundo dos adultos. Isto significa que através da participação nas brincadeiras de suas culturas, crianças adquirem motivos e competências que lhes permitem agir em ambientes específicos cheios de regras, valores e normas que limitam seu comportamento. 
O estudo de Winther-Lindqvist (2012) associou a Teoria Histórico-cultural com a teoria das representações sociais, discutida por Moscovici, e o desenvolvimento de identidades sociais, discutido por Duveen, para compreender o desenvolvimento das identidades sociais das crianças e de seus motivos durante a passagem da Educação Infantil para o Ensino Fundamental I. Miettinen (2005) mostrou que, no ambiente profissional do trabalho, o desejo de reconhecimento, compreendido como artefato mediador, é um recurso que faz surgir motivos em atividades coletivas em empresas. No Brasil, há estudos em Educação Matemática que se esforçam para mostrar a relação entre motivos e sentido pessoal (PALMA, 2010; ASBAHR, 2011) e motivos como apropriações do discurso social (TORISU, 2014).

Quando Skovsmose et al. (2009) nos dá a ideia de que o background de um indivíduo refere-se às suas raízes culturais, compreendo tais raízes como o conjunto de vivências, relações e aprendizagens (valores, crenças, regras) que ocorrem em práticas sociais, como as citadas anteriormente: família, escola, trabalho. De maneira análoga, quando pensamos que o foreground relaciona-se às possibilidades futuras que uma pessoa enxerga para si, estamos admitindo que esse foreground é resultado das mesmas vivências. Como é no seio dessas vivências, relações e aprendizagens que surgem os motivos, investigar backgrounds e foregrounds de uma pessoa nos dará pistas desse surgimento. No caso dos alunos deste estudo - motivos para a participação em tarefas matemáticas.

A investigação de backgrounds e foregrounds tem sido discutida por alguns autores em Educação Matemática (ALRØ; SKOVSMOSE, 2010; SKOVSMOSE, et al., 2009; SKOVSMOSE, et al., 2012; BERNARDI; CALDEIRA; DUARTE, 2012; BIOTTO FILHO, 2015).

Skovsmose et al. (2009) investigaram os foregrounds de alguns estudantes indígenas, da tribo brasileira Kopenoty. Eles verificaram que as diferentes razões e intenções para que eles se envolvessem com a aprendizagem matemática podiam estar relacionadas aos tipos de significados atribuídos por eles à Matemática, vindos à tona por meio da investigação dos seus foregrounds. Dentre esses significados, destacam-se o significado instrumental, que parece estar relacionado às necessidades da vida do estudante como, por exemplo, passar em exames vestibulares, e o significado cotidiano, que se relaciona à utilidade da Matemática em situações diárias, como o trabalho no campo. Skovsmose et al. (2012) mostraram que, para seis estudantes de uma favela de São Paulo, as intenções de aprendizagem também estavam relacionadas a seus foregrounds. Embora os sujeitos das duas pesquisas estivessem inseridos em realidades sociais bastante distintas, os estudantes que moravam na favela também atribuíram à Matemática um significado instrumental. 
Por outro lado, podemos verificar, por meio de alguns dados fornecidos pelos autores dos dois artigos que os backgrounds dos estudantes indígenas influenciaram de forma distinta os seus foregrounds, quando comparados aos dos estudantes da favela.

No caso dos estudantes indígenas, o significado instrumental dado à Matemática tinha relação com a possibilidade de ter uma profissão futura que os capacitasse a ajudar seu povo. Um dos estudantes desejava ser enfermeiro e uma das estudantes desejava ser professora de crianças, ambos com o propósito de voltar à aldeia, após a conclusão dos cursos. As suas vivências, os valores aprendidos e outros aspectos da vida na aldeia que compunham o repertório de seus backgrounds criavam o desejo de retornar ao convívio com seu grupo.

Para os estudantes da favela, o valor instrumental da Matemática também se relacionava à possibilidade de ter uma futura profissão, não para voltar para lá, mas sim, sair de lá. Eles vislumbravam um futuro em outro lugar e a rota de fuga para isso era margeada pelo sucesso profissional. Diferentemente dos indígenas, o passado dos estudantes da favela era composto por situações que eles não desejavam reviver. Entretanto, isso não significa que foregrounds sejam determinados, exclusivamete, por backgrounds. Isso corrobora a ideia de Biotto Filho (2015), quando o autor afirma que os backgrounds são importantes para compreendermos aspectos do foreground, mas que o primeiro não deve ser considerado como fator determinante do segundo.

Um aspecto importante a respeito de backgrounds e foregrounds é que eles não são imutáveis, embora backgrounds sejam mais estáveis. As pessoas podem "interpretar e reinterpretar antecedentes e experiências passadas" (SKOVSMOSE et al., 2009, p. 223), reinterpretando, com isso, seus backgrounds. Da mesma forma, a ocorrência de mudanças em suas vidas (por exemplo, o seu meio social, as suas condições econômicas ou as do país) podem alterar seus foregrounds. Novas e diferentes expectativas para o futuro podem surgir. Pode ocorrer, também, que mudanças na estrutura social e econômica minem os foregrounds das pessoas, ao que Skovsmose (2007) denomina foreground arruinado (ruined foreground). Para o autor, foregrounds arruinados podem obstaculizar a aprendizagem.

No presente estudo, a um grupo de quatro estudantes foram propostas tarefas investigativas na aula de Matemática. A intenção era saber os seus motivos para participação nessas tarefas e uma hipótese inicial era de que eles estariam relacionados à própria tarefa e, como consequência, à Matemática nela contida. No entanto, ao analisar os dados, percebi que há motivos ligados a outros momentos de suas vidas e interesses para o futuro, ou seja, ligados aos seus backgrounds e foregrounds.

A seguir, apresento os aspectos metodológicos do estudo para aclarar o caminho 
percorrido.

\section{Aspectos metodológicos}

Nesta pesquisa, de abordagem qualitativa, os sujeitos foram quatro estudantes do nono ano do Ensino Fundamental de uma escola pública da cidade de Belo Horizonte, Minas Gerais, com idades que variavam de 14 a 17 anos. O grupo foi escolhido porque seus membros foram mais frequentes às aulas nas quais os dados foram coletados, permitindo a composição de um conjunto denso de material para análise. Seus nomes fictícios eram Paulo, Lauro, Leandro e Gabriel. Uma caracterização mais detalhada desses estudantes será realizada mais adiante.

Durante o segundo semestre de 2012, período em que estive em sala como pesquisador para um estudo de doutorado, propus aos estudantes algumas tarefas investigativas nos moldes dos cenários para investigação (SKOVSMOSE, 2000), com a ajuda da professora de Matemática da turma, presente em todas as aulas. Os cenários para investigação se opõem ao paradigma do exercício, uma abordagem de ensino na qual os conteúdos e técnicas matemáticas são ensinados somente para que o estudante resolva uma lista de exercícios que, geralmente, possuem uma única resposta. Em cenários para investigação que são "por natureza abertos [...], os alunos podem formular questões e planejar linhas de investigação de forma diversificada" (ALRØ; SKOVSMOSE, 2010, p. 55), dirigindo, em alguma medida, seu processo de aprendizagem.

Algumas tarefas faziam referência a situações da semirrealidade (SKOVSMOSE, 2000), ou seja, situações nas quais se "desconsidera aspectos ou pormenores que seriam importantes em acontecimentos reais" (BIOTTO FILHO, 2015), mas que, quando exploradas utilizando investigações, podem contribuir sobremaneira para uma educação matemática menos mecanicista. Uma delas estava relacionada a planos de telefonia celular e os estudantes deveriam criar um usuário hipotético para, dentre várias opções de planos oferecidos por diferentes empresas, também hipotéticas, escolher aquela que melhor atenderia o usuário, em termos de serviços e com menor custo. Para isso, efetuaram vários cálculos para chegar ao melhor plano e justificaram a escolha.

Em outra, os estudantes precisavam fazer uma previsão de gastos necessários a uma reforma hipotética das salas de aula da escola e entregá-la à direção. Nesta tarefa, eles utilizaram vários conhecimentos, como o cálculo de áreas e a conversão entre unidades de medidas de comprimento. Entretanto, havia propostas próximas de atividades com referência à Matemática pura (SKOVSMOSE, 2000), como uma que solicitava aos estudantes a ampliação (ou redução) das figuras que compõem o Tangram. 
Pretendia-se que essas tarefas trouxessem um novo sabor às aulas, de modo que pudéssemos acessar motivos para a participação do grupo. Sendo assim, após findarem as tarefas investigativas, entrevistei os estudantes pela primeira vez, acerca de seus motivos para o aceite ao convite. Isso ocorreu no final do ano de 2012. Naquele primeiro momento, a entrevista foi realizada em uma sala da escola com os quatro participantes reunidos e guiada por uma pergunta que basicamente procurava saber por que eles participavam de tarefas como aquelas que propus. Entretanto, em algumas respostas percebi elementos das vidas dos estudantes, não relacionados diretamente às tarefas e que pareciam influenciar seus motivos. Fiquei interessado, então, em saber um pouco mais de suas vidas. Sem me desviar do objetivo inicial, agora estava interessado em saber de outros aspectos das vivências desses estudantes em grupos sociais que pudessem gerar motivos para a participação nas tarefas propostas.

Decidi explorar de forma mais minuciosa as vidas dos alunos, realizando uma nova entrevista, agora individual. Um pouco diferente do que ocorrera na primeira entrevista, na qual os estudantes pareciam estar preocupados em mostrar uma visão utilitária da Matemática, na segunda, eles estavam mais à vontade e as perguntas não faziam menção direta aos porquês de suas participações nas tarefas. No repertório de respostas, os estudantes falaram de assuntos diversos, como família, escola, futuro, amigos...

Havia interesse que eles se revelassem por meio de suas declarações, de modo que eu pudesse enxergá-los em suas vivências com seus grupos e perceber como esses grupos poderiam influenciar seus motivos. Isto é coerente com as ideias de Freitas (2002, p. 29) sobre entrevistas em pesquisa qualitativa de cunho socio-histórico, quando ela afirma que, "na entrevista, é o sujeito que se expressa, mas sua voz carrega o tom de outras vozes, refletindo a realidade de seu grupo, gênero, etnia, classe". É também coerente com o que Kvale (1996 apud SKOVSMOSE et al., 2009) denomina entre-vista.

Assim como na entrevista, uma entre-vista não é um encontro fortuito, como aqueles que ocorrem diariamente pelos corredores. Há intenções de ambos os lados. O entrevistador deseja obter informações que lhe interessam e o entrevistado pode ter várias intenções: ajudar em uma pesquisa, divulgar suas ideias, etc. Por outro lado, é comum que as pessoas compreendam a entrevista como um jogo no qual ocorre uma dissimetria entre os envolvidos e que pode, de acordo com Bourdieu (1997 apud BUENO, 2002), ser potencializada pela dissimetria social quando o pesquisador, de alguma forma ou por julgamento prévio, ocupa posição superior ao entrevistado. Não é o que se deseja quando realizamos uma entre-vista.

A entre-vista é uma formulação que permite estabelecer um diálogo respeitoso, no qual, ambos, entrevistador e entrevistado, desejam colaborar um com o outro. Os participantes da 
entre-vista refletem conjuntamente sobre as declarações, de modo a se chegar a uma compreensão bastante fiel do que se quer expor. Não há agenda oculta, de modo que o entrevistado sabe claramente das intenções do entrevistador (SKOVSMOSE et al., 2009). Não se estabelece relação de poder. Na entre-vista todos estão em um mesmo plano e os dois lados detêm saberes importantes que podem ser comungados, constituindo-se em um bom procedimento para desvendar backgrounds e foregrounds. O segundo encontro com os estudantes foi nos moldes de uma entre-vista.

A seguir, apresento, de forma mais pormenorizada o que ocorreu na entrevista e na entrevista.

\subsection{Buscando motivos - entrevista}

A primeira entrevista ocorreu poucos dias após a última tarefa, de modo que eles se lembravam com clareza do que haviam feito.

Nela, a pergunta-diretriz procurava saber o principal porquê dos alunos para participarem das tarefas investigativas propostas. Os quatro estudantes estavam juntos, mas cada um teve oportunidade de responder, individualmente. Entretanto, foi uma entrevista engessada pela pergunta-diretriz e eles não tiveram muitas oportunidades de se desviar. Abaixo, alguns excertos das entrevistas:

Pesquisador: Quando vocês se envolvem neste tipo de tarefa em sala de aula, há um porquê principal? Se sim, qual?

Paulo: Eu acho que a gente faz pensando no futuro, né? (pausa) Se a gente precisar fazer... igual lá, tem os cálculos lá que a gente ... Ai, vai que no futuro a gente precisa, né? ${ }^{2}$

Lauro: [...] Eu acho que tem um porquê sim. Porque, de certa forma ele (o pesquisador) passa algumas atividades relacionadas à Matemática, mas também cotidianas [...] algumas coisas que você pode relacionar com o cotidiano que te ajudam. A própria questão do celular e tudo.

Pesquisador: Então você acha que a Matemática, não toda, né, em algum momento, ela pode te ajudar depois, no seu cotidiano?

Lauro: Exatamente, num futuro trabalhista.

Gabriel: Mais por causa do dia a dia mesmo... A gente pode precisar do negócio lá... Aí a gente sabe fazer qual vale a pena.

Leandro: Eu também era daqueles alunos que pensava assim ... pra que eu tô usando isso aí? Ai, depois veio aquela do celular e eu entendi mais ou menos porque que a gente tava fazendo aquilo... porque tipo assim, às vezes você tinha um plano do jeito que você queria, mas você podia achar um mais barato, dependendo da quantidade... Aí vi que você pode usar no dia a

${ }^{2}$ As respostas foram transcritas praticamente sem alterações. 
dia, igual todo mundo falou assim.

Essa entrevista foi iniciada e concluída no mesmo dia. O curioso nessas respostas é que, ao se referirem aos temas das tarefas, os estudantes o fizeram sempre recordando aquelas que pareciam mostrar uma Matemática útil no cotidiano, na visão deles. Em nenhum momento eles citaram as tarefas que tinham um apelo mais matemático. Isso parecia sugerir que havia um motivo mais importante para a participação dos estudantes, que estava relacionado a uma visão utilitária da Matemática, em particular, no cotidiano e no futuro.

Nos artigos de Skovsmose et al. (2009, 2012), já citados neste texto, esse significado cotidiano foi ressaltado nas respostas dadas pelos estudantes indígenas e pelos estudantes moradores de uma favela de São Paulo. Isso mostra, em alguma medida, que motivos relacionados a uma Matemática útil para o cotidiano parecem mover estudantes rumo à participação em tarefas matemáticas, independentemente de suas realidades sociais, uma vez que os estudantes indígenas, os estudantes da favela e os estudantes do presente estudo fazem parte de distintos meios sociais.

Na minha interpretação, baseada em uma perspectiva histórico-cultural de que motivos são de caráter social, podemos pensar que os estudantes vivem em grupos: família, escola, amigos e que, dentro desses grupos se apropriam de valores culturais, normas, regras, modos de pensar e se expressar que passam a fazer parte de seus backgrounds eforegrounds. Parece natural, portanto, que eles reproduzam em suas falas o discurso de seu meio. Contudo, por que grupos com realidades distintas podem revelar um mesmo motivo para aprender Matemática? Acredito que, nesse caso, isso ocorre porque possuem aspectos comuns em seus backgrounds e foregrounds, os quais denominarei aspectos de ampla abrangência.

A visão utilitária/cotidiana da Matemática parece ser um aspecto de ampla abrangência que faz parte dos backgrounds de todos os estudantes (inclusive os dos estudantes indígenas e moradores da favela) por ser parte de um inconsciente coletivo que atribui à Matemática um papel quase vital para a vida das pessoas. Uma fala de Lauro parece ser reflexo desse julgamento que a sociedade faz da Matemática e corrobora o que foi discutido acima. Ele disse: "pra sociedade você tem que saber, pelo menos, um mínimo de Matemática [...] pra você interagir com as pessoas e tudo, você tem que saber um mínimo de Matemática. Na hora de pegar um ônibus, digamos assim..." (Entrevista com Lauro, 2012).

Outras respostas dos quatro estudantes nesses mesmos termos também parecem refletir influências do discurso dos outros sobre a Matemática. Aspectos de ampla abrangência podem ser compreendidos como parte comum dos repertórios dos backgrounds e foregrounds de um 
grupo grande de pessoas e podem explicar, na minha compreensão, motivos comuns para que elas desejem aprender algo, ainda que façam parte de grupos com realidades socioeconômicas e culturais distintas.

A maneira de compreender os motivos até agora apresentados pelos estudantes me leva a fazer a seguinte pergunta: se aprender uma Matemática útil é um motivo relacionado a aspectos de ampla abrangência de seus backgrounds e foregrounds, que outros motivos eles revelariam e que fossem mais particulares?

Para investigá-los realizei uma entre-vista com cada um dos estudantes alguns meses mais tarde. De acordo com Skovsmose et al. (2009), o foreground não é encontrado em sua forma pura exigindo que, na entre-vista, haja um compartilhamento dos significados das expectativas que os entrevistados manifestam. Não definimos uma pergunta-diretriz e privilegiamos as vivências dos estudantes. Passamos agora à breve apresentação dos estudantes ao leitor. Outras particularidades de suas vidas serão conhecidas por meio de suas respostas à entre-vista, nas seguintes categorias: família, Matemática, escolha da escola, futuro e lazer.

\subsection{Retratos tornando-se cenas das vidas dos alunos e vislumbrando o que virá: a entre- vista}

Era meu desejo que as entre-vistas fossem agradáveis, sem nenhum caráter compulsório. Havia alguns encaminhamentos, mas, dependendo da resposta, a direção mudava e eu podia acessar um novo momento da vida do estudante. Era como se, em alguns momentos, os fatos de suas vidas, já passados, já inertes, já retratos, se reavivassem em suas palavras, constituindose em cenas reais em minha mente. Em outros, os alunos imaginaram cenas possíveis para suas histórias.

\section{Paulo}

Paulo tinha 15 anos à época da pesquisa. Embora elogiado pela professora e reconhecido pelos colegas como um aluno exemplar e de excelentes resultados nas provas, isso não parecia envaidecê-lo. Era dedicado, participativo, mas não falava muito. Morava em um condomínio fechado na região metropolitana de Belo Horizonte com os pais e mais um irmão. A situação financeira da família era confortável.

\section{Família}

A minha família é fundamental para minha vida, dentro e fora da escola. Eles me proporcionam 
ótimas condições de estudo, como por exemplo: compram o livro que minha escola sugere, atendem a todas as minhas reclamações em termos de condições de estudo. A minha família me apoia muito com meus estudos, principalmente a minha mãe. Várias vezes ela deixa de sair para se divertir para ficar em casa comigo porque eu tenho que estudar. Além disso, o fato de eles me darem tudo o que eu peço me motiva estudar cada dia mais para mostrar para eles que estou fazendo valer a pena. O apoio dos meus pais quando as coisas não dão certo também é muito importante, pois me motiva a não desistir e me mostra a minha capacidade.

(Entre-vista com Paulo, 2013).

\section{Escolha da escola}

A escolha de ir para o CP não foi minha. Na verdade eu estudei durante a $1^{a}$ série em uma escola de meu bairro [...]. Porém, por grande pressão de minha mãe, meu pai me inscreveu no sorteio do CP e eu fui sorteado. Então mudei de escola porque minha família considerava o CP melhor por vários aspectos, como: fica dentro da UFMG, me direciona para o Colégio Técnico e etc.

(Entre-vista com Paulo, 2013).

\section{Matemática}

Minha relação com a matemática, até o $8^{\circ}$ ano, foi sempre normal. Mas a partir do $8^{\circ}$ ano eu me apaixonei por Matemática, só não gostava mais do que Educação Física. Agora no CP continuo gostando muito de Matemática e isso é fundamental, pois esse meu gosto me facilita a aprender as coisas em sala, e como eu não tenho muito tempo para estudar essa matéria em casa devido ao fato de eu dar prioridade ao curso técnico. Então esse meu gosto por Matemática sempre me ajudou muito.

(Entre-vista com Paulo, 2013).

\section{Futuro}

Ainda não sei se vou fazer curso superior, depende muito do meu futuro, se eu conseguir um bom emprego como técnico, talvez eu nem pense em faculdade. Eu escolheria, hoje, cursar Ciência da Computação porque é uma matéria em que eu me identifico muito.

(Entre-vista com Paulo, 2013).

\section{Lazer}

Eu só consigo me divertir quando estou com a consciência totalmente leve, ou seja, quando não tenho que estudar ou fazer um trabalho. Então, minha diversão favorita é jogar futebol, depois é jogar vídeo game. Para mim, isso compensa toda a minha semana de estudos e todo meu estresse com provas. Eu participo de um grupo que se reúne para jogar futebol aos fins de semana, mas esse grupo é formado em sua maioria por meus familiares e seus amigos.

(Entre-vista com Paulo, 2013).

\section{Leandro}

Diferente de Paulo, Leandro era muito falante e tinha 14 anos. Morava em um bairro da região metropolitana de Belo Horizonte com a mãe, o padrasto e mais quatro irmãos. Ao falar de sua família, centrou-se na mãe e em um dos irmãos. A mãe de Leandro era vendedora no centro da cidade e cumpria uma rotina diária de trabalho bastante exaustiva.

\section{Família}


Ela mesma fala que a única coisa que ela está deixando para mim é o estudo. Minha mãe fala isso todo dia praticamente. Lá em casa a minha mãe apostou tudo em mim, porque o meu irmão do meio não está nem ai para nada. Minha mãe falou: olha, eu já abri mão dele, porque eu sei que ele tem problema. Agora tá em você.

(Entre-vista com Leandro, 2013).

\section{Escolha da Escola}

A minha mãe ficou sabendo por uma amiga dela que a escola era uma escola boa, dentro da UFMG. Ai quando você fala que estuda dentro da UFMG parece que... Ai minha mãe foi lá e fez a inscrição.

(Entre-vista com Leandro, 2013).

\section{Matemática}

Eu não me dou muito bem com a Matemática não. Às vezes eu erro muita coisa boba e tiro nota ruim. [...] a matéria foi ficando mais dificil e eu deixei de gostar. Deixa eu falar uma coisa para você: eu gosto da matéria demais, mas quando... nossa... você tá doido... bate um desânimo. Você vê assim, todo mundo tirando nota boa e vê você lá... você tenta às vezes... por isso que às vezes eu falo: eu largo de mão mesmo, não estudo para a prova não. Se eu sei, eu sei. Se eu não sei, não vou aprender de um dia para o outro estudando.

(Entre-vista com Leandro, 2013).

\section{Futuro}

Em relação ao futuro profissional, ele parecia ainda confuso. No início da entre-vista, disse ter vontade de ser o primeiro da família a concluir um curso superior e justificou utilizando sua mãe como exemplo:

Porque eu vejo minha mãe. Às vezes minha mãe poderia ser melhor do que ela é hoje porque falta para ela um curso superior, um ensino maior para ela.

(Entre-vista com Leandro, 2013).

Mais à frente, parecia não ter certeza sobre isso, já que o curso técnico poderia lhe dar retorno financeiro, sem necessidade do curso superior. Sobre esse assunto, Leandro disse:

Depende se, tipo assim, se eu ver que o salário, a remuneração do curso que eu tenho está muito alta e se eu fizer um curso superior não vai fazer muita diferença, vou continuar fazendo o técnico. [...] Vou ver como é que é primeiro. Aí, se eu ver que não é necessário ir para a faculdade eu vou continuar exercendo o técnico.

Meus interesses são os seguintes: eu queria ter uma empresa. Eu queria comandar a empresa, mas para tudo você precisa saber alguma coisa. Administração é exatas, eu não vou conseguir fugir da Matemática. [...] eu gosto da área de exatas, mesmo tendo esses problemas todos, eu ainda vou para o lado de exatas. [...] A minha preocupação é esta: dar alguma coisa para a minha mãe.

(Entre-vista com Leandro, 2013).

\section{Lazer}

Para se divertir, Leandro não parecia ter muitas opções. Perguntado sobre o que gostava de fazer nas horas livres, ele disse que jogava bola e dormia muito. Não gostava muito de filmes e nem de jogar videogame, mas adorava "soltar papagaio". Ele me ensinou que o inverno é a 
melhor época para soltar papagaio, porque o vento é intenso. Em relação aos filmes em cinemas, mesmo quando decidia assisti-los, nem sempre tinha dinheiro, porque a situação financeira da família era delicada.

\section{Gabriel}

Gabriel era o mais calado do grupo. Muito tímido, exibia um sorriso envergonhado sempre que era questionado sobre alguma coisa. Tinha 16 anos à época da pesquisa. Ele havia sido reprovado duas vezes na escola e, por essa razão, estava fora da faixa etária comumente encontrada em turmas de nono ano, entre 13 e 15 anos. Essas reprovações provocaram sentimentos negativos em relação ao espaço escolar, declarados por ele:

Gabriel: [...] Eu repeti duas vezes lá. Aí eu fiquei com raiva. Eu não gostava muito de participar não.

(Entre-vista com Gabriel, 2013).

\section{Família}

Morava em uma casa grande de um bairro da região metropolitana de Belo Horizonte com mais seis pessoas: pai, mãe, irmã, avó, avô e bisavó. Seu pai havia estudado contabilidade, mas não trabalhava na área. A família era unida e, sempre que possível, faziam algumas refeições juntos. Além disso, cobrava dele bom desempenho escolar e o ajudavam quando necessário:

Todo mundo almoça junto. Só meu pai que chega tarde. Aí ele almoça separado. Fora isso almoça e janta todo mundo junto. Aí, domingo almoça todo mundo junto.

Incentivam e quando eu tô com dificuldade eu falo com eles... quem nem Português. Agora eu tô fazendo aula particular e tal, desde o ano passado. Que eu tenho dificuldade em português. Ai eu comecei.

(Entre-vista com Gabriel, 2013).

\section{Escolha da escola}

Minha mãe ficou sabendo, não me lembro por quem... eu sei que ela ficou sabendo e me inscreveu lá no sorteio. Ai eu fui sorteado. Ela colocou também pensando no Colégio Técnico e esses negócios...

(Entre-vista com Gabriel, 2013).

\section{Matemática}

Tipo, eu não sou muito bom em Matemática, mas, tipo, se tiver que escolher entre fazer exatas, humanas e esses negócios, eu acho que eu vou me dar melhor em exatas.

Matemática eu também sou, uns sessenta, setenta por cento, minhas notas. Mas só que, tipo, pelo menos eu acho que Matemática você faz muito exercício e tal, aí você consegue aprender e tal. Agora Português você tem que ler muito para entender.

(Entre-vista com Gabriel, 2013).

Isso soava paradoxal, já que, mesmo não tendo bons resultados, Gabriel informou que 
queria aprender Matemática e justificou da seguinte maneira:

É porque tipo, ninguém quer ser pobre. Aí, pra mim, tipo, ser rico e tal eu vou ter que estudar, mesmo que eu não goste daquilo e tal, vou ter que me dedicar de qualquer jeito.

(Entre-vista com Gabriel, 2013).

\section{Futuro}

Mas tipo, eu tô pensando o seguinte: se eu gostar do técnico, eu vou trabalhar com ele. Aí, se eu ver que não tá muito bom, aí tipo, eu pretendo fazer Educação Física, ou então alguma coisa na área de exatas. Eu quero formar aqui, primeiro. Fazer estágio, trabalhar um tempo no técnico, ver se eu gosto. Se eu não gostar vou entrar numa boa faculdade, ter minha casa, esses negócios.

(Entre-vista com Gabriel, 2013).

\section{Lazer}

Eu gosto, tipo, de ficar na rua conversando com meus colegas. Gosto de ir ao cinema, mas eu vou de vez em quando e tal, quando tem um filme que me interessa muito. Tipo, vai ter 'O homem de ferro' [...] suspense às vezes é bom. Também gosto muito de assistir seriado. [...] de vez em quando futebol. Não sou muito bom de futebol.

(Entre-vista com Gabriel, 2013).

\section{Lauro}

Lauro tinha 14 anos quando estive em sua sala. Não falava muito, mas quando o fazia, expunha com clareza suas ideias. Não utilizava muitas gírias como é comum entre os adolescentes.

\section{Família}

Morava com a mãe em um bairro na mesma região do colégio onde estudava. Como os pais são separados, os finais de semana eram reservados ao pai, que morava em outro bairro. A relação entre eles era bastante harmoniosa, sem conflitos. Sua mãe trabalhava fora e, dentro das possibilidades, ela e o pai proporcionavam a Lauro uma vida confortável.

\section{Escolha da escola}

Olha, na verdade quem escolheu o CP foi meu pai, pela passagem direta para o Colégio Técnico. Ele que foi lá e fez o sorteio. Aí, quando eu passei foi a felicidade maior dele.

(Entre-vista com Lauro, 2013).

Na escola eu sempre fui bem em Matemática. Sempre gostei também. Só que nono ano eu tive um desempenho muito baixo na primeira etapa, por causa de questões de família. Meu avô estava internado. Eu tava abalado e também tava tendo dificuldade na matéria. Só que, na segunda etapa, quando entrou uma matéria nova e eu comecei prestar atenção, ai já voltei a me dar bem (Entre-vista com Lauro, 2013).

\section{Futuro}

Perguntei, também, se ele pretendia fazer um curso superior. Diferentemente de Paulo e 
Leandro, Lauro não pretendia experimentar a carreira como profissional da área técnica, antes de ir à universidade. Tão logo terminasse o curso técnico, desejava cursar Engenharia de Software. Sobre este desejo, ele disse:

Eu quero fazer Engenharia de Software. Já vou fazer direto.

(Entre-vista com Lauro, 2013).

\section{Lazer}

Quando questionado sobre o que fazia nas horas de lazer, Lauro nos disse que fazia aulas de tênis duas vezes por semana e aulas de inglês, também duas vezes por semana. Além disso, ele disse que jogava futebol nos fins de semana na quadra que existia no condomínio onde seu pai morava e "assisto à TV o tempo todo e computador... redes sociais e jogos" (Entre-vista com Lauro, 2013).

\section{Que motivos emergiram durante a entre-vista?}

Como já discutido, na minha interpretação, baseada em Skovsmose et al. (2009), o background e o foreground têm relação com experiências e aprendizagens que a pessoa viveu/vive. Parte dessas aprendizagens pode tornar-se estrutural na construção do conjunto de valores que a pessoa considera para sua vida. Nas respostas dadas pelos estudantes percebemos que as vivências e aprendizagens nos grupos pareciam impulsioná-los. Da mesma forma, as expectativas e desejos para o futuro também cumpriam esse papel.

Partindo das interpretações das respostas dos estudantes, apresento os motivos que surgiram durante as entre-vistas, em cada uma das categorias citadas anteriormente.

\section{Família}

Para todos os estudantes a família parecia ser nuclear em suas vidas. Paulo disse que a família era fundamental, dentro e fora da escola. Pode-se notar, pela sua resposta, o esforço que os pais faziam para proporcionar-lhe uma boa educação. Leandro morava com a mãe e o padrasto, este último, pelo que pareceu, sem muita influência sobre ele. Entretanto, a mãe trabalhava como vendedora para que ele pudesse estudar em uma boa escola. Em contrapartida, ela declaradamente depositava nele todas as esperanças de um futuro melhor para a família. A família de Gabriel era muito unida e o apoiava nos estudos quando era necessário, pagando aulas particulares, por exemplo. Lauro era bem assessorado pelos pais que tentavam lhe proporcionar boa qualidade de vida, o que significava, também, estudar em uma boa escola e 
estudar um segundo idioma.

Todos os quatro estudantes percebiam os esforços das suas famílias para que tivessem uma boa educação. Como reconhecimento, um motivo que pode ter surgido foi o de cumprir o papel de estudante realizando a tarefa. Corresponder às expectativas dos pais sendo alunos cumpridores dos seus deveres era um motivo para que participassem das tarefas investigativas. Uma fala de Paulo é bastante ilustrativa do que quero dizer: "Além disso, o fato de eles me darem tudo o que eu peço me motiva estudar cada dia mais para mostrar para eles que estou fazendo valer a pena" (Entre-vista com Paulo, 2013).

\section{Escolha da escola}

A escolha da escola era uma decisão dos pais e isso ficou claro nas respostas. Além da escola ser considerada de boa qualidade, acredito que o seu maior atrativo era a garantia da vaga em uma escola técnica de renome. Muitos pais consideram o curso técnico uma boa opção para o filho aprender uma profissão, antes de ir para o curso superior.

A preocupação dos pais em matricular os filhos em uma boa escola revela a valorização que davam aos estudos. Tal valorização, muito provavelmente, foi passada aos filhos, que compreendiam a importância dos estudos para eles e para os próprios pais. Nesse sentido, o motivo estudar para ingressar na escola técnica também pode ter surgido como resultado das vivências em casa.

Percebem-se, nessa categoria, influências do background e do foreground no surgimento do motivo. A apropriação do discurso social, reproduzido pelos pais, que propala a necessidade de se estudar em uma boa escola, parece estar relacionada ao background dos estudantes. Como consequência do estudo em boas escolas, o indivíduo pode ter sucesso profissional e financeiro e isso parecia ser uma expectativa dos estudantes. Essa perspectiva parece se relacionar aos seus foregrounds.

\section{Matemática}

Os estudantes Paulo e Lauro gostavam de Matemática e a tinham como uma das disciplinas favoritas. Os históricos de ambos mostravam que, ao longo da vida escolar, a aprendizagem da Matemática se deu sem grandes obstáculos, de modo que a relação com essa disciplina era bastante amigável. Nos casos de Leandro e Gabriel, a relação com a Matemática, em termos de rendimento, não era boa. Suas performances não eram das melhores e havia um desânimo para os estudos. Dessa forma, para Paulo e Lauro, gostar de Matemática e ter bons resultados na disciplina pareciam ser motivo para que eles participassem das tarefas. No caso 
de Leandro e Gabriel, o motivo associado à Matemática parecia ser somente a utilidade prática dos conteúdos matemáticos na vida cotidiana e para o futuro.

Nessa categoria, podemos perceber como as experiências anteriores, associadas ao background, influenciaram motivos, sobretudo as positivas. Paulo e Lauro eram movidos pelo motivo gostar de Matemática, dadas as suas boas experiências anteriores nessa disciplina.

\section{Futuro}

As respostas a essa categoria foram muito interessantes e mostraram elementos dos foregrounds dos estudantes de forma clara. Paulo, Leandro e Gabriel iriam tentar a carreira técnica, antes de cogitar outra possibilidade: “[...] se conseguir um bom emprego como técnico, talvez eu nem pense em faculdade"; "[...] se eu ver que o salário, a remuneração do curso que eu tenho está muito alta e se eu fizer um curso superior não vai fazer muita diferença, vou continuar fazendo o técnico"; "[...] se eu gostar do técnico, eu vou trabalhar com ele [...]" (Entre-vistas, 2013). Eles pretendiam concluir o curso técnico e, com o diploma em mãos, iniciar um trabalho na área escolhida, supostamente para ganhar dinheiro. A opção de ir para a universidade só foi aventada caso esse plano desse errado.

Mesmo Leandro, que nos disse desejar ser o primeiro de sua família a concluir um curso de nível superior, disse que antes tentaria emprego como técnico, talvez porque fosse um caminho abreviado para ajudar a sua mãe.

Lauro foi o único a dizer que não priorizaria o trabalho como técnico, afirmando que iria direto para a universidade cursar engenharia.

Ter um futuro de sucesso parecia ser um dos desejos de Paulo, Lauro, Leandro e Gabriel e estudar tornava-se uma das necessidades a serem satisfeitas para a realização desse sonho e a Matemática seria importante nesse processo. Lauro deixou isso muito claro em uma de suas falas quando disse que as tarefas propostas poderiam ajudá-lo em um futuro trabalhista. Leandro e Gabriel, embora não gostassem de Matemática, escolheriam, caso fossem para a universidade, um curso na área de exatas. No caso de Leandro, muito provavelmente porque, no seu julgamento, cursos nessa área poderiam ajudá-lo em seu objetivo de ganhar dinheiro e ajudar sua família. Gabriel foi mais explícito. Para ele, valia o sacrifício de estudar o que não gostava (no caso, a Matemática) para ser rico. Ele disse: “É porque tipo, ninguém quer ser pobre. Ai, pra mim, tipo, ser rico e tal eu vou ter que estudar, mesmo que eu não goste daquilo e tal, vou ter que me dedicar de qualquer jeito" (Entre-vista com Gabriel, 2013).

Relacionado ao futuro, podemos supor que um motivo para a participação nas tarefas propostas é aprender Matemática para um futuro de sucesso financeiro. Nesse momento cabe 
uma pequena discussão, mas não menos importante, sobre o conceito de posição de fronteira $\mathrm{e}$ como o vejo inserido neste estudo.

Para Skovsmose et al. (2012, p. 236), a posição de fronteira é aquela "de onde o indivíduo pode ver suas atuais condições de vida em relação a outras possibilidades de vida". Embora posições de fronteira possam existir para todos, se a pessoa vive em situação marginal, percebe de forma mais acentuada as diferenças entre sua vida e aquela que está ali, bem perto, mas inatingível e que é vivida por outros. Geralmente, estudos que colocam o conceito de posição de fronteira em relevo estão relacionados a grupos marginalizados, que não parece ser o caso dos nossos estudantes. Talvez a vida de Leandro fosse a que destoasse, um pouco, das de seus colegas

Leandro levava uma vida mais difícil, se comparada às de Paulo e Lauro, cujas famílias possuíam uma condição socioeconômica mais confortável. Paulo morava em condomínio fechado, Lauro jogava tênis e estudava inglês. Leandro, por sua vez, nem podia ir ao cinema por falta de dinheiro e, talvez por isso, tenha se tornado um exímio empinador de pipas. Todos desejavam ganhar dinheiro como profissionais de sucesso. Entretanto, para Leandro, ter sucesso profissional e financeiro serviria para ajudar sua mãe. O que ele disse sobre isso:

Porque eu vejo minha mãe. Às vezes minha mãe poderia ser melhor do que ela é hoje porque falta para ela um curso superior, um ensino maior para ela. [...] a minha preocupação é esta: dar alguma coisa para a minha mãe.

(Entre-vista com Leandro, 2013).

Entendo que Leandro, mesmo fazendo parte do mesmo grupo da escola, desejava ultrapassar a fronteira para o lado em que alguns de seus amigos já estavam. O conceito de posição de fronteira tem sido explorado para grupos, geralmente vivendo à margem da sociedade, como nos casos já citados neste artigo. O grupo da escola do qual Leandro fazia parte não parece ser um grupo marginalizado. No entanto, em alguns aspectos, Leandro parece estar à margem quando observamos um contraste entre sua vida e as de alguns de seus colegas.

Contudo, para transpor a barreira inicial, será necessário Leandro transpor outra barreira: aquela que o separa do mundo dos que dominam a Matemática. Ao afirmar "Meus interesses são os seguintes: eu queria ter uma empresa. Eu queria comandar a empresa, mas para tudo você precisa saber alguma coisa. Administração é exatas, eu não vou conseguir fugir da Matemática" (Entre-vista com Leandro, 2013), o saber matemática torna-se um caminho para mudar de lado. O que quero dizer é o seguinte: talvez seja importante discutirmos a ideia de posição de fronteira de uma pessoa dentro de um mesmo grupo. Pessoas em um mesmo grupo podem experimentar sensações de não pertencimento a ele, mesmo sendo pertencentes a ele. Leandro pertencia ao mesmo grupo de alunos da escola. 


\section{Lazer}

As respostas dadas nesta categoria não me permitiram perceber motivos para a participação nas tarefas.

\section{Considerações finais}

Os quatro estudantes desta pesquisa apresentaram um motivo explícito para participarem das tarefas investigativas que lhes foram propostas: aprender uma Matemática útil para o cotidiano, o que, na minha interpretação, se deve a aspectos de ampla abrangência de seus backgrounds e foregrounds. Entretanto, devemos lembrar que, na perspectiva históricocultural, motivos emergem no interior das relações sociais que ocorrem diariamente nos grupos dos quais fazemos parte. Nessas vivências, nós nos apropriamos de valores, regras e conhecimentos que formam um conjunto que cria uma estrutura orientadora de nossas vidas. Isso faz parte de nossos backgrounds. Por outro lado, o nosso entorno, a conjuntura econômica e social que diante de nós se descortina, também influenciam nossas expectativas e perspectivas para o futuro, nossos foregrounds. Nesse sentido, dos backgrounds e foregrounds emergem motivos para a aprendizagem.

Entretanto, backgrounds e foregrounds não são estruturas imutáveis da vida de uma pessoa, como se existisse um determinismo social do qual ela não pudesse se desviar. Eles podem mudar, sobretudo o foreground. O conhecimento de backgrounds e foregrounds dos estudantes, por parte do professor, pode ter implicações pedagógicas importantes como, por exemplo, guiar suas ações de modo que se tornem mais próximas das expectativas do grupo de estudantes.

As atividades investigativas deste estudo, voltadas a situações da semirrealidade, mostraram aos estudantes que, em alguma medida, a Matemática pode realmente ser útil às nossas vidas. Da maneira como foram conduzidas, as atividades podem ter criado o que Alrø e Skovsmose (2010) denominam vistas privilegiadas. Elas permitiram aos estudantes perceberem as tarefas sob outra perspectiva, atribuindo-lhes um significado. Em vez de uma resposta baseada no senso comum, de que a Matemática é importante para a vida, os estudantes talvez tenham percebido, por meio das atividades, a utilidade da Matemática em situações de sua própria vida.

Outra discussão realizada e que considero importante tem relação com o alargamento da ideia de posição de fronteira. Estando na mesma escola, poderíamos supor todos os estudantes com as mesmas condições socioeconômicas, afinal, estão no mesmo meio: o escolar. 
Contudo, um olhar mais detalhado sobre os alunos sujeitos da pesquisa mostrou que, mesmo compartilhando vários momentos de suas vidas, Leandro parecia estar em uma posição de fronteira por duas razões principais: a situação socioeconômica inferior à de seus colegas e os insucessos na disciplina Matemática. Parece interessante, portanto, que, ao olharmos para a escola com lentes ampliadas, vejamos os alunos que, mesmo estando ali, naquele mesmo grupo podem estar à margem. Com isso, a barreira invisível da fronteira parece existir em situações não tão óbvias.

O professor, atento a tudo isso, poderá possibilitar aos seus alunos assumir outro papel, no qual eles não sejam coadjuvantes em seu processo de aprendizagem. Com isso, eles, os alunos, poderão nos ensinar muito, inclusive que o inverno tem os melhores ventos para soltar papagaio.

\section{Agradecimento}

À CAPES, pela concessão da bolsa de doutorado.

\section{Referências}

ALRØ, H.; SKOVSMOSE, O. Diálogo e aprendizagem em Educação Matemática. 2. ed. Belo Horizonte: Autêntica, 2010. (Tendências em Educação Matemática).

AMES, C. Classrooms: goals, structures and student motivation. Journal of Educational Psychology, Washington, v. 84, n. 3, p. 261-271, set. 1992.

ASBAHR, F. S. F. Por que aprender isso professora? Sentido pessoal e atividade de estudo na Psicologia Histórico-cultural. 2011. 220f. Tese (Doutorado em Psicologia) - Instituto de Psicologia, Universidade de São Paulo, São Paulo, 2011.

BERGIN, D. A. Influences on classroom interest. Educational Psychologist, Philadelfia, v. 34, n. 2, p. 87-98, 1999.

BERNARDI, L. T. M. S.; CALDEIRA, A. D.; DUARTE, C. G. Educação Matemática na Escola Indígena sob uma Abordagem Crítica. Boletim de Educação Matemática, Rio Claro, v. 26. n. 42B, p. 409-431, abril. 2012.

BIOTTO FILHO, D. Quem não sonhou em ser um jogador de futebol? Trabalho com projetos para reelaborar foregrounds. 2015. 234f. Tese (Doutorado em Educação Matemática) - Instituto de Geociências e Ciências Exatas, Universidade Estadual Paulista Júlio de Mesquita Filho, Rio Claro, 2015.

BUENO, C. M. O. Entre-vista: espaço de construção subjetiva. 1. ed. Porto Alegre: Edipucrs, 2002.

BZUNECK, J. A. Como motivar os alunos: sugestões práticas. In: BORUCHOVITCH, E.; BZUNECK, J. A.; GUIMARÃES, S. R (Org.). Motivação para aprender: aplicações no contexto educativo. Petrópolis: Editora Vozes, 2010. p. 13-42.

CHAIKLIN, S. A conceptual perspective for investigating motive in cultural-historical theory. In: 
HEDEGAARD, M.; EDWARDS, A.; FLEER, M. Motives in children's development: culturalhistorical approaches. New York: Cambridge University Press, 2012. p. 209-224.

CORSARO, W. A.; RIZZO, T. A. Discussione and friendship: socialization processes in the peer culture of italian nursery school children. American Sociological Review, Thousand Oaks, v. 53, n. 6, p. $879-894$, dezembro. 1988 .

FREITAS, M. T. A. A abordagem sócio-histórica como orientadora da pesquisa qualitativa. Cadernos de Pesquisa, São Paulo, v. 1, n. 116, p. 21-40, julho. 2002.

HEDEGAARD, M. The dynamics aspects in childen's learning and development. In: HEDEGAARD, M.; EDWARDS, A.; FLEER, M. Motives in children's development: cultural-historical approaches. New York: Cambridge University Press, 2012. p. 09-27.

MEDINA, J. S.; MARTINEZ, V. Developing motivation through peer interaction: a cross-cultural analysis. In: HEDEGAARD, M.; EDWARDS, A.; FLEER, M. Motives in children's development: cultural-historical approaches. New York: Cambridge University Press, 2012. p. 97-114.

MIETTINEN, R. Object of activity and individual motivation. Mind Culture and Activity, New York, v. 12, n. 1, p. 52- 69, 2005.

PALMA, R. C. D. A produção de sentidos sobre o aprender e ensinar matemática na formação inicial de professores para a Educação Infantil e anos iniciais do Ensino Fundamental. 2010. 196f. Tese (Doutorado em Educação) - Faculdade de Educação da Universidade Estadual de Campinas, Campinas, 2010.

SKOVSMOSE, O. Cenários para investigação. Bolema, Rio Claro, v. 13, n. 14, p. 66-91, 2000.

SKOVSMOSE, O. et al. A aprendizagem matemática em uma posição de fronteira: foregrounds e intencionalidade de estudantes de uma favela brasileira. Bolema, Rio Claro, v. 26, p. 231-260, 2012.

SKOVSMOSE, O. et al. Antes de dividir temos que somar: "entre-vistando" foregrounds de estudantes. Bolema, Rio Claro, v. 22, n. 34, p. 237-262, 2009.

SKOVSMOSE, O. Foregrounds and politics of learning obstacles. In: GELLERT, U.; JABLONKA E. Mathematisation - demathematisation: Social, philosophical, sociological and educational Ramifications. Rotterdam: Sense Publishers, 2007. p. 81-94.

TORISU, E. M. Motivos para envolvimento em tarefas investigativas em aulas de Matemática à luz da Teoria da Atividade: um estudo com alunos do Ensino Fundamental. 2014. 203f. Tese (Doutorado em Educação: Educação Matemática) - Faculdade de Educação, Universidade Federal de Minas Gerais, Belo Horizonte, 2014.

WINTHER-LINDQVIST, D. Developing social identities and motives. In: HEDEGAARD, M.; EDWARDS, A.; FLEER, M. Motives in children's development: cultural-historical approaches. New York: Cambridge University Press, 2012. p. 115-132.

Submetido em 16 de Julho de 2017. Aprovado em 15 de Fevereiro de 2018. 